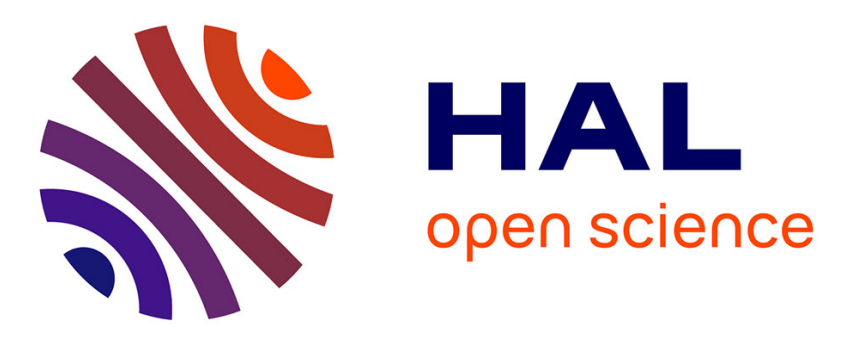

\title{
Formation of metallic nanoclusters in oxygen deficient indium tin oxide films
}

\author{
Jacques Perriére, Christian Hébert, Aline Petitmangin, Xavier Portier, \\ Wilfried Seiler, Magdalena G. Nistor
}

\section{- To cite this version: \\ Jacques Perriére, Christian Hébert, Aline Petitmangin, Xavier Portier, Wilfried Seiler, et al.. Forma- tion of metallic nanoclusters in oxygen deficient indium tin oxide films. Journal of Applied Physics, 2011, 109 (12), pp.123704- 123714. 10.1063/1.3596578 . hal-02456537}

\section{HAL Id: hal-02456537 \\ https://hal.science/hal-02456537}

Submitted on 27 Jan 2020

HAL is a multi-disciplinary open access archive for the deposit and dissemination of scientific research documents, whether they are published or not. The documents may come from teaching and research institutions in France or abroad, or from public or private research centers.
L'archive ouverte pluridisciplinaire HAL, est destinée au dépôt et à la diffusion de documents scientifiques de niveau recherche, publiés ou non, émanant des établissements d'enseignement et de recherche français ou étrangers, des laboratoires publics ou privés. 


\title{
Formation of metallic nanoclusters in oxygen deficient indium tin oxide films
}

\author{
J. Perrière, ${ }^{1}$ C. Hebert, ${ }^{1}$ A. Petitmangin, ${ }^{1}$ X. Portier,${ }^{2}$ W. Seiler, ${ }^{3}$ and M. Nistor ${ }^{4, a)}$ \\ ${ }^{1}$ Institut des Nanosciences de Paris (INSP), CNRS UMR 7588, Université Pierre et Marie Curie - Paris 6, \\ 4 Place Jussieu, 75252 Paris cedex 05, France \\ ${ }^{2}$ CIMAP, CEA/CNRS UMR 6252/ENSICAEN/UCBN, 6 Boulevard du Maréchal Juin, 14050 Caen Cedex, \\ France \\ ${ }^{3}$ PIMM, UMR CNRS 8006 Arts et Métiers ParisTech, 151 Boulevard de l'Hopital, 75013 Paris, France \\ ${ }^{4}$ National Institute for Lasers, Plasmas and Radiation Physics, Plasma Physics and Nuclear Fusion Laboratory, \\ L22 P.O. Box. MG-36, 77125 Bucharest-Magurele, Romania
}

\begin{abstract}
The composition, structure, microstructure, and properties of indium tin oxide films grown by pulsed laser deposition at room temperature and under vacuum were studied. The films are highly nonstoichiometric, with about $20 \%$ oxygen deficiency, and present a semiconductor behavior between 300 and $15 \mathrm{~K}$, followed by a superconducting transition at about $7 \mathrm{~K}$ related to the presence of In or In-Sn nanoclusters embedded in a stoichiometric indium tin oxide matrix, i.e., nanocomposite films are formed by the phase separation of oxygen deficient metastable indium tin oxide. The solid-liquid and liquid-solid phase transitions of the metallic nanoclusters were evidenced by resistivity measurements in the 300 to $450 \mathrm{~K}$ range. The films grown at room temperature are partially crystallized. Actually, stoichiometric indium tin oxide crystallites are observed in the as grown films. After thermal treatment $(<450 \mathrm{~K})$, both stoichiometric indium tin oxide crystallites and the tetragonal phase of the metallic In are observed in the nanocomposite films. The size of nanoclusters (from 5 to $30 \mathrm{~nm}$ ), which depends on the thermal treatments and crystallization, and the microstructure of the nanocomposite films were confirmed by HRTEM measurements.
\end{abstract}

\section{INTRODUCTION}

The growth and properties of indium based oxide films have been and are widely studied for optoelectronic applications including photovoltaic, liquid crystal displays, light emitting diodes, ${ }^{1,2}$ which need a high optical transmittance in the visible range and a low resistivity. The literature shows that films of pure indium oxide or indium based oxide like indium tin oxide (ITO) present a very particular behavior as a function of the oxygen pressure during the growth, with the formation of transparent and highly conducting or absorbing and slightly conducting films, ${ }^{3-9}$ the presence of metallic In grains in the films has been reported..$^{9}$ Moreover, the optimization of the physical properties of such films often needs low temperature treatments under reducing or oxidizing ambient, and numerous works dealing with this optimization process have been carried out. ${ }^{10-16}$ As a result, crystallization temperatures ranging from 100 to $250{ }^{\circ} \mathrm{C}$ have been reported for ITO films grown by different techniques, and within the temperature range $150-165^{\circ} \mathrm{C}$ for films deposited by energetic processes (pulsed-laser deposition or sputtering). ${ }^{16}$ These low temperature treatments lead to low value of resistivity via the film crystallization and/or activation of dopants.

More recently, the formation of oxygen deficient indium based oxide films has been the subject of studies, since interesting specific properties were observed in such films. Indeed, the oxygen content in oxide films is known to have significant effect on their properties, ${ }^{17,18}$ and oxygen deficient

${ }^{\text {a)} E l e c t r o n i c ~ m a i l: ~ m n i s t o r @ i n f i m . r o . ~}$ indium oxide thin films obtained by vacuum annealing developed thus metallic conductivity, ${ }^{19}$ with a metal-semiconductor transition at low temperature ${ }^{20}$ very similar to those observed in other oxides. ${ }^{21}$ Moreover, such undoped vacuum annealed indium oxide films exhibit room temperature ferromagnetism..$^{20}$ On the other hand, an abrupt resistivity decrease, i.e., an insulator-metal like transition, has been observed in oxygen deficient $\mathrm{Al}$ doped indium zinc oxide, ${ }^{22}$ and in addition, a resistive switching induced by pulse electrical current has been evidenced in gallium indium oxide films. ${ }^{23}$ It has been also reported ${ }^{24}$ that highly nonstoichiometric ITO films grown by the pulsed electron beam deposition method ${ }^{25,26}$ are not stable, leading thus to a phase separation with metallic In or In-Sn nanoparticles embedded in a stoichiometric ITO matrix, i.e., formation of nanocomposite films. ${ }^{24}$ Resistivity measurements as a function of temperature on such films evidence the superconducting transition in the metallic clusters, as well as their melting and freezing temperatures through corresponding changes in the film resistivity. ${ }^{24}$

In order to give some insights on the basic phenomena underlying these various experimental facts, we have studied the composition, structure, microstructure, and physical properties of oxygen deficient ITO films grown by pulsed laser deposition (PLD) at room temperature and annealed at low temperatures $\left(<150{ }^{\circ} \mathrm{C}\right)$. Owing to some of its specificities (growth under vacuum and moderate deposition rate leading to crystallization at low temperature), PLD is well suited to study the effects of the oxygen deficiency in this low temperature domain. Actually, the large oxygen deficiency (about 
$20 \%$ of oxygen missing) in these ITO films leads to the formation of metallic nanoclusters of In or In-Sn embedded in a stoichiometric ITO matrix through a phase separation, ${ }^{24}$ which occurred even at room temperature. Resistivity measurements as a function of temperature and transmission electron microscopy evidenced the effects of the temperature on metallic nanoclusters size distribution and crystallization. This low temperature formation of metallic nanoclusters in indium based oxide films could have interesting applications in the field of next generation of nonvolatile storage devices.

\section{EXPERIMENTAL SET-UP}

ITO thin films (50 to $100 \mathrm{~nm}$ thick) were grown at room temperature on either c-cut sapphire single crystal or TEM copper grids, by PLD under vacuum $\left(10^{-7} \mathrm{mbar}\right)$. PLD was performed using a frequency quadrupled pulsed Nd:YAG laser ( $7 \mathrm{~ns}$ duration pulses at a $5 \mathrm{~Hz}$ repetition rate). Pulses in the 50 to $200 \mathrm{MW} / \mathrm{cm}^{2}$ range irradiated at a $45^{\circ}$ angle of incidence the $\mathrm{In}_{1.8} \mathrm{Sn}_{0.2} \mathrm{O}_{3}$ (ITO) target. Further details of the PLD setup are given elsewhere. ${ }^{27}$

The thickness, composition, and in-depth distribution of the elements of the ITO films were determined by Rutherford backscattering spectrometry (RBS). ${ }^{4} \mathrm{He}^{+}$ion beams in the 1.7 to $1.8 \mathrm{MeV}$ energy range were used according to the experiments. The incident beam was normal to the samples, and backscattered particles were detected at $165^{\circ}$. These RBS measurements were carried out at the SAFIR IBA laboratory, University Pierre and Marie Curie. The limited mass resolution of RBS does not permit to distinguish the respective In and $\mathrm{Sn}$ contribution. It was thus assumed that the cationic composition of the target $\left(\mathrm{In}_{1.2} \mathrm{Sn}_{0.2} \mathrm{O}_{3}\right)$ is maintained in the films owing to the congruence of the PLD method. The concentration profile of the elements in the films was obtained by the RUMP simulation program. ${ }^{28}$ For the simulation, it was considered that the films are only composed of In and $\mathrm{O}$. The crystalline structure of the films was studied by $\mathrm{x}$-ray diffraction analyses (XRD) in the Bragg-Brentano geometry, using the Philips Xpert diffractometer with the $\mathrm{Cu}$ radiation at the PIMM (Arts et Metiers ParisTech). The films were investigated by transmission electron microscopy (TEM) using a JEOL 2010 FEG microscope operated at 200 $\mathrm{kV}$. TEM images were recorded using a Keenview $2 \mathrm{kx} 2 \mathrm{k}$ $\mathrm{CCD}$ camera. Image processing was performed by the commercial GATAN software called Digitalmicrograph. The films devoted to such measurements were grown on thin holey carbon coated TEM copper grids. To obtain the composition and film thickness, a c-cut sapphire substrate was put close to the TEM grid, and this sample was used as a reference. The resistivity of the ITO films as a function of temperature was measured by the classical four probe method with ex-situ deposited gold contacts. For the resistivity measurements two experimental set-ups were used: one for measurements at low temperature (from room temperature, $300 \mathrm{~K}$ down to liquid helium temperature, $4 \mathrm{~K}$ ) and the other for high temperature measurements (from 300 up to $450 \mathrm{~K}$ ). In the first case, the cooling ( 300 to $4 \mathrm{~K}$ ) and heating (4 to 300 $\mathrm{K}$ ) rates were $3 \mathrm{~K}$ per minute, the sample being in He vapor. In the second case, the heating (300 to $450 \mathrm{~K}$ ) and cooling
(450 to $300 \mathrm{~K}$ ) rates were about $2 \mathrm{~K}$ per minute, the samples being under atmosphere during these treatments.

\section{RESULTS AND INTERPRETATIONS}

Studies of the PLD oxide film growth ${ }^{29}$ have shown that the oxygen incorporation can be controlled by the oxygen pressure and/or the laser power density. ${ }^{30}$ Widely oxygen deficient indium tin oxide films were thus obtained in this work by PLD under vacuum ( $\left.10^{-7} \mathrm{mbar}\right)$ and high laser power density $\left(10^{8} \mathrm{~W} / \mathrm{cm}^{2}\right)$. As a matter of fact, Fig. 1 represents the RBS spectrum recorded on such a film and it shows a large oxygen deficiency as indicated by the oxygen composition profile (deduced from the use of the RUMP simulation program) given in inset. An overall $\left(\mathrm{In}_{1.2} \mathrm{Sn}_{0.2} \mathrm{O}_{2.4}\right)$ composition is obtained, i.e., about $20 \%$ of oxygen atoms are missing. Such a result is very similar to those obtained by $\mathrm{PED}^{24}$ which led to the formation of nanocomposite films with metallic In or In-Sn nanoclusters embedded in a stoichiometric ITO matrix. The presence of such metallic nanoclusters can be rapidly checked through the variation of their physical (optical or electrical) properties with temperature. ${ }^{24}$ Resistivity measurements $[\mathrm{R}(\mathrm{T})]$ from room temperature to liquid $\mathrm{He}$ temperature were thus performed. Indeed, In and $\mathrm{Sn}$ being superconducting in the bulk form $(3.4$ and $3.5 \mathrm{~K}$, respectively), nanoclusters of In, Sn, and/or of In-Sn (with variable compositions), embedded in the films, will present also a superconducting transition. ${ }^{31,32}$

Figure 2 shows the $\mathrm{R}(\mathrm{T})$ curve for an $\mathrm{In}_{1.2} \mathrm{Sn}_{0.2} \mathrm{O}_{2.4}$ film grown by PLD at $10^{-7}$ mbar and room temperature. A semiconductor like behavior is observed between 300 and $15 \mathrm{~K}$, followed by a superconducting transition with a $\mathrm{T}_{\mathrm{c}}$ onset estimated to $8 \mathrm{~K}$, i.e., a behavior very similar to those previously reported for oxygen deficient $\mathrm{ITO}^{24}$ or indium oxide, ${ }^{31,32}$ and which can be explained by the presence of metallic clusters in the films, giving rise to the superconducting transition. The zero resistivity is not reached, indicating that the density of metallic nanoclusters is not sufficient to

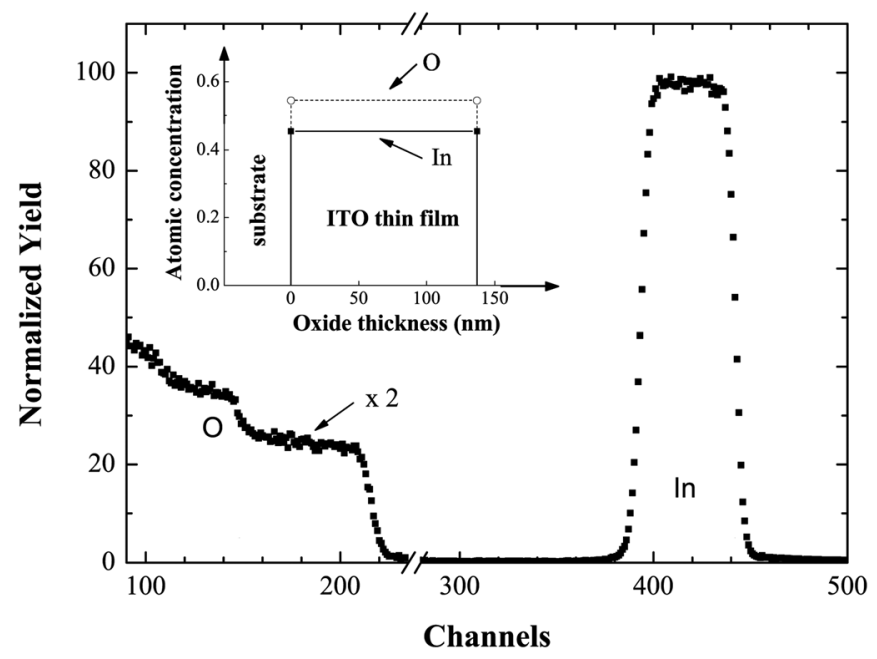

FIG. 1. RBS spectrum $\left({ }^{4} \mathrm{He}^{+} 1.7 \mathrm{MeV}, 2.916 \mathrm{keV} /\right.$ channel and 194.544 $\mathrm{keV}$ for energy of channel 0 ) of the ITO film grown by PLD on a single crystal c-cut sapphire substrate at $10^{-7} \mathrm{mbar}$ and room temperature before the resistivity measurements in the temperature range 300 to $450 \mathrm{~K}$. The inset shows the in-depth oxygen and indium atomic concentrations of the film. 


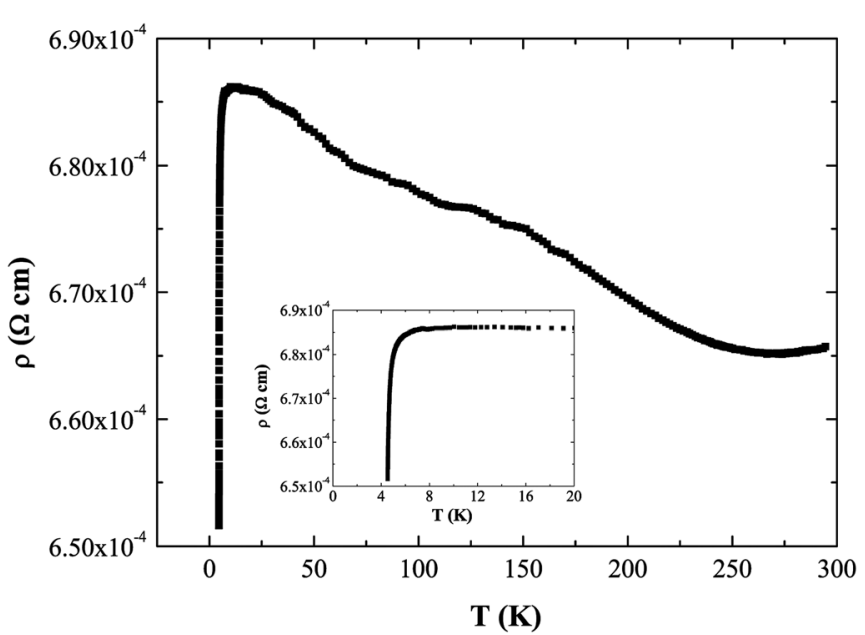

FIG. 2. Temperature dependence of the resistance R(T) (from the room temperature to liquid $\mathrm{He}$ ) for the ITO film grown by PLD on a single crystal c-cut sapphire substrate at $10^{-7} \mathrm{mbar}$ at room temperature.

ensure electrical conduction via a percolating path. However, the presence of this superconducting transition evidences that the following phase separation, leading to the formation of metallic clusters in a stoichiometric ITO matrix, may occur even at a low $\mathrm{T}(300 \mathrm{~K})$ during the PLD of oxygen deficient ITO films.

$$
\begin{gathered}
\left(\mathrm{In}_{1.8} \mathrm{Sn}_{0.2}\right) \mathrm{O}_{2.4} \rightarrow \alpha\left(\operatorname{In}_{1.8} \mathrm{Sn}_{0.2}\right) \mathrm{O}_{3} \\
+\sum_{x=0}^{2.4} \beta_{x}\left(\operatorname{In}_{1.8} \mathrm{Sn}_{0.2}\right) \mathrm{O}_{2.4-x} .
\end{gathered}
$$

In this phase separation, the stable stoichiometric phase grows at the expense of the sub-oxide, ${ }^{33}$ and in the extreme case $(x=2.4)$, the formation of metallic clusters can occur. ${ }^{24}$

The effects of thermal treatments (from 300 to $450 \mathrm{~K}$ ) on oxygen deficient ITO films have been followed in situ by $\mathrm{R}(\mathrm{T})$ measurements, since metallic In or In-Sn clusters undergo melting and solidification in this temperature range, with consequences on the film resistivity. ${ }^{24}$ Figure 3 represents the $R(T)$ curve upon heating under ambient atmosphere in the 300 to $450 \mathrm{~K}$ range, and shows an increase in the film resistivity between 315 and about $370 \mathrm{~K}$. This variation is associated with the melting of the In-Sn clusters, whose resistivity in the liquid state is higher than that in the solid state. ${ }^{34}$ With further heating ( 375 to $430 \mathrm{~K}$ ), a measurable decrease of the resistivity values occurs. Upon cooling the resistivity is at first slightly increasing in the 430 to $330 \mathrm{~K}$, and then a rapid decrease occurs upon solidification of the In-Sn clusters. Finally the value of resistivity at $300 \mathrm{~K}$ after the heating and cooling cycle is lower than the initial value. This means that an irreversible transformation has occurred in the ITO film upon the heating-cooling cycle.

A second heating/cooling cycle in the 300 to $450 \mathrm{~K}$ has been carried out on this film and is presented in Fig. 4. This figure shows a hysteresis loop corresponding to the solidliquid transition in metallic clusters upon heating and to the liquid-solid transition upon cooling. ${ }^{24}$ The corresponding melting $T_{m}$ and solidification $T_{\mathrm{f}}$ temperatures, $T_{m}=350 \mathrm{~K}$ and $\mathrm{T}_{\mathrm{f}}=325 \mathrm{~K}$ are both lower than the melting temperature

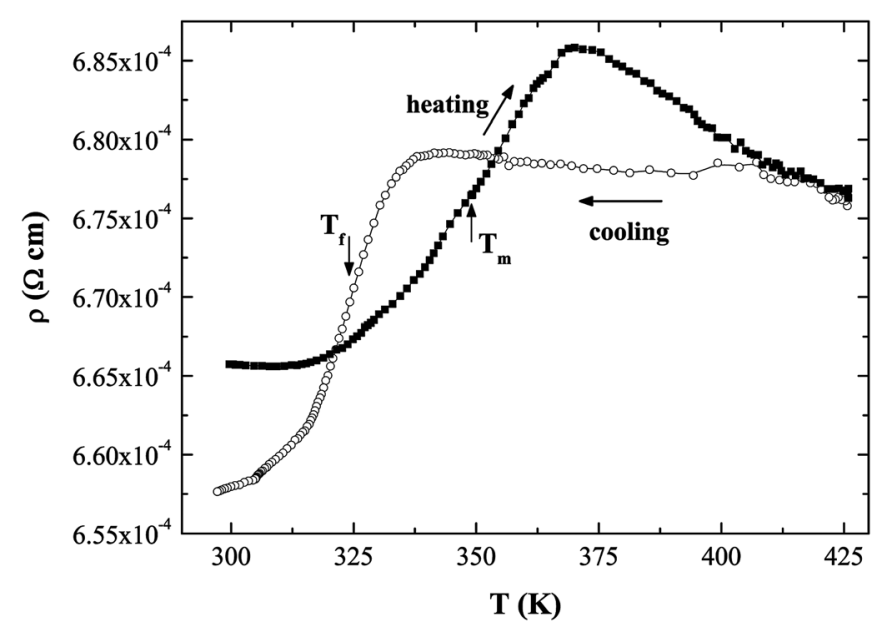

FIG. 3. Temperature dependence of the resistivity upon heating from 300 to $450 \mathrm{~K}$ (full rectangles) and then upon cooling from 450 to $300 \mathrm{~K}$ (open circles) for an ITO film grown by PLD on a single crystal c-cut sapphire substrate at $10^{-7}$ mbar at room temperature.

of the bulk InSn alloy ( $395 \mathrm{~K}$ ) or In (430 K). These observations are very similar to those already reported in the case of metallic $\mathrm{In}^{24}$ or Ga clusters, ${ }^{35}$ and are specific properties of metallic clusters embedded in a solid matrix [35 and references herein cited]. Moreover, Fig. 4 confirms that an irreversible modification of the matrix has taken place during the first heating-cooling cycle (Fig. 3). As the measurements were carried out in air in the temperature range of $300-450 \mathrm{~K}$, two phenomena can occur in the ITO films: an oxidation of films which had initially a large oxygen deficiency and/or a crystallization of these films.

RBS analyses were performed on the thermal treated film and the RBS spectrum presented in Fig. 5 has to be compared to Fig. 1 corresponding to the same but as grown film. A significant change in the overall oxygen content is not observed, the variation of the number of oxygen atoms (less than 3\%) being lower than the RBS accuracy on the oxygen determination (about 4\%). However, the depth distribution of the oxygen shows significant differences as evidenced by

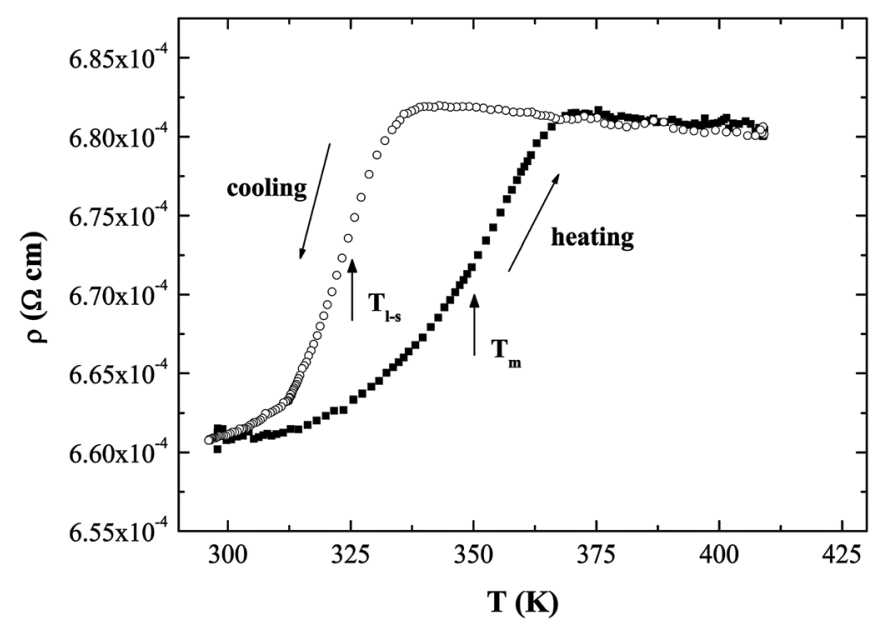

FIG. 4. Temperature dependence of the resistivity upon a second heatingcooling cycle for an ITO film grown by PLD on a single crystal c-cut sapphire substrate at $10^{-7}$ mbar at room temperature: heating from 300 to 450 $\mathrm{K}$ and then upon cooling from 450 to $300 \mathrm{~K}$. 


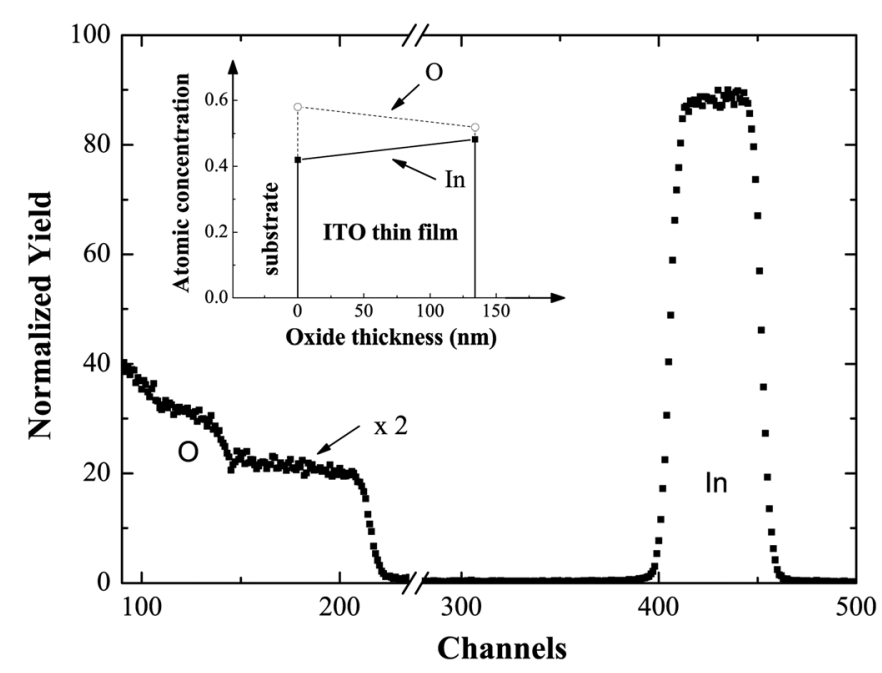

FIG. 5. RBS spectrum $\left({ }^{4} \mathrm{He}^{+} 1.8 \mathrm{MeV}, 2.910 \mathrm{keV} /\right.$ channel and 255.141 $\mathrm{keV}$ for energy of channel 0 ) of the ITO film grown by PLD on a single crystal c-cut sapphire substrate at $10^{-7} \mathrm{mbar}$ at room temperature after two heating-cooling cycles of the resistivity measurements in the temperature range 300 to $450 \mathrm{~K}$. The inset shows the in-depth oxygen and indium atomic concentrations of the film.

the comparison of the insets in Figs. 1 and 5. Actually oxygen enrichment is observed toward the interface with the substrate and corresponding oxygen depletion is present in the near surface region of the film, the reverse being observed for the indium concentration. Such a difference must be associated with atomic movements (inward diffusion of oxygen and/or outward cations diffusion) during the thermal treatment. These atomic movements are facilitated by the presence of liquid clusters in the film for $\mathrm{T}>375 \mathrm{~K}$ (see Fig. 3). The absence of oxygen incorporation during the thermal treatment can appear a priori surprising. However, the oxygen reaching the film is in molecular form. The dissociation of these molecules at the film surface to form atomic oxygen which can be incorporated is certainly the limiting factor of oxidation. Moreover, the short duration of the treatment (about 30 mins) can explain the absence of incorporation of oxygen.

The in-depth oxygen distribution in Fig. 5 gives rise to the following question: what is the reason of such oxygen enrichment near the interface with the substrate? Indeed, inward and outward oxygen movements should occur with equal probability, leading thus to a uniform oxygen distribution. An increase in oxygen concentration at the film-substrate interface could only occur if the oxygen atoms are fixed in this region, i.e., strongly bonded in an oxide network. The crystalline state of the ITO films before (as grown film) and after the thermal treatment (after the second cycle shown in Fig. 4) was therefore studied by $\mathrm{x}$-ray diffraction analysis and the results are presented in Fig. 6 .

The main reflection peaks observed on the diagram corresponding to the as-deposited film in Fig. 6 can be identified with the main (hkl) planes of the bixbyite phase of the $\mathrm{In}_{2} \mathrm{O}_{3}$ structure (JCPDS file number 6-416), ITO being known to crystallize in the same structure. The large increase in intensity toward the lower diffraction angles $\left(2 \theta<25^{\circ}\right)$ characterizes the presence of an important amount of amorphous

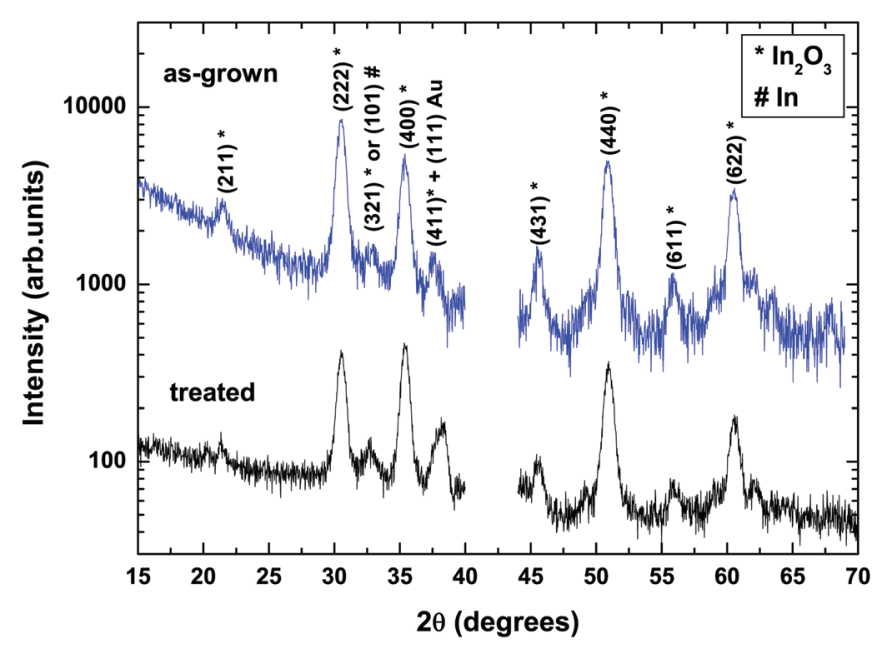

FIG. 6. (Color online) X-ray diffraction pattern for an ITO film grown by PLD on a single crystal c-cut sapphire substrate (a) at room temperature and (b) after the thermal treatment in the 300 to $430 \mathrm{~K}$ temperature range.

material in the film grown at room temperature. After the treatment (from 300 to $450 \mathrm{~K}$ ), an additional peak appears $\left(2 \theta=38^{\circ}\right)$ due to the presence of the Au contacts needed for the $\mathrm{R}(\mathrm{T})$ measurements on the sample. To quantitatively compare these XRD diagrams, for each (hkl) peak, we determined the integrated intensity $\mathrm{I}_{\mathrm{hkl}}$ after substracting the background. Then the values of the $\mathrm{I}_{\mathrm{hkl}} / \mathrm{I}_{222}$ ratio were deduced and are presented in Table I. For comparison purpose, the $I_{h k 1} / I_{222}$ values calculated from the JCPDS file are also given in Table I.

The comparison of the data for the film grown at room temperature and the JCPDS file shows that the film is not randomly oriented, weak textures [(400) and (440) orientations] are evidenced, may be related to the growth under low oxygen pressures as it has been observed. ${ }^{15}$ After thermal treatment, a noticeable increase of the $\mathrm{I}_{400} / \mathrm{I}_{222}$ and $\mathrm{I}_{440} / \mathrm{I}_{222}$ values indicates an increase of the concentration and/or size of the stoichiometric ITO crystallites with the (400) and (440) textures with respect to the substrate during the treatment.

The peak located at $2 \theta \approx 33^{\circ}$ in the diagrams can be identified with the (321) planes of the bixbyite phase $\left(2 \theta=33.103^{\circ}\right)$. However, it could also correspond to the (101) lattice reflection of the tetragonal metallic In phase $\left(2 \theta=32.964^{\circ}\right)$. For the film as-deposited, as indicated in Table I, the ratio of the (321) (and (101) indium) and (222) integrated intensity peaks is about 0.05 , while the value deduced from the JCPDS file of the $\mathrm{In}_{2} \mathrm{O}_{3}$ bixbyite phase is 0.02 , indicating the possible presence of metallic In or In-Sn clusters at this stage. After thermal treatment, this ratio is about 0.13. Even if the accuracy of the measurements is rather poor (about 15\%), a large difference exists with the theoretical value, and a contribution of the (101) plane of the indium phase can thus be concluded.

All the preceding results have been obtained on a single one sample. However, these experiments have been routinely reproduced. Actually, all the $\mathrm{In}_{1.8} \mathrm{Sn}_{0.2} \mathrm{O}_{\mathrm{x}}$ films with $x<2.75$ gave resistivity measurements similar to those reported in Fig. 2 with a semiconducting behavior followed at low $\mathrm{T}$ by the abrupt decrease in resistivity, i.e., onset of 
TABLE I. The ratio of the few integrated X-ray intensity peaks on (222) reflection peak for the ITO thin films as deposited and after thermal treatment.

\begin{tabular}{|c|c|c|c|c|c|c|}
\hline & $(211) /(222)$ & $(101)$ or $(321)^{a} /(222)$ & $(400) /(222)$ & $(431) /(222)$ & $(440) /(222)$ & $(622) /(222)$ \\
\hline RT & 0.085 & 0.05 & 0.59 & 0.13 & 0.60 & 0.38 \\
\hline Treated & 0.075 & 0.13 & 1.13 & 0.15 & 0.93 & 0.40 \\
\hline JCPDS & 0.14 & 0.02 & 0.3 & 0.1 & 0.35 & 0.25 \\
\hline
\end{tabular}

${ }^{\mathrm{a}}$ The $(321)$ planes of the bixbyite phase $\left(2 \theta=33.103^{\circ}\right)$ or the $(101)$ lattice reflection of the tetragonal metallic In phase $\left(2 \theta=32.964^{\circ}\right)$.

superconductivity. The precise value of resistivity was a function of thickness and experimental conditions (the deposition rate). In the same way, the XRD analyses gave the same results presented in Fig. 6, with some variations in the peak intensity, i.e., an increase in deposition rate leading to a decrease of XRD intensity.

The treatment of the oxygen deficient ITO films in the 300 to $430 \mathrm{~K}$ range leads thus to the growth of both ITO and In crystalline grains. Complementary insights on the microstructure were obtained by TEM analysis on ITO thin films grown on a copper grid at room temperature and $150{ }^{\circ} \mathrm{C}$. Bright field images, selected area electron-diffraction (SAED) patterns and high resolution techniques were used for further analysis.

Figure 7(a) shows a typical bright field image of an ITO film grown at room temperature, while Fig. 7(b) corresponds to a film grown at $150{ }^{\circ} \mathrm{C}$. In these images, the dark and gray regions correspond to diffracting ITO and/or In-Sn grains. It appears clearly a different grain size comparing the two images. At room temperature, a mean diameter of crystallites was estimated at about 5 to $10 \mathrm{~nm}$, whereas for the film grown at $150{ }^{\circ} \mathrm{C}$, this mean diameter increases in the range of 10 to $50 \mathrm{~nm}$, indicating a better crystallization of the overall film but, from these images, there is no way to know whether the In phase is formed or not.

Figure 8 exhibits the corresponding SAED patterns. The diffuse diffraction rings corresponding to the film grown at room temperature [Fig. 8(a)] indicate a rather poorly crystallized film, containing a significant volume of amorphous material. However, the four most intense diffraction rings are clearly identified with the four most intense rings of the bixbyite phase, indicating thus the presence of stoichiometric ITO crystallites in the film. The presence of In (or In-Sn) grains cannot be deduced from such a pattern. In Fig. 8(b), the SAED pattern of the film grown at $150{ }^{\circ} \mathrm{C}$ shows well defined rings indicating a better crystallinity. Moreover, in addition to the twelve most intense rings of the bixbyite phase, three weak diffraction rings corresponding to the [(101), (110), and (112)] planes of the In tetragonal phase are also visible. These latest lines confirm the presence of small size and low concentration of In (or In-Sn) nanograins in the film, together with a high density of ITO crystallites, in good agreement with the results of x-ray diffraction measurements.

Figure 9(a) is a typical HRTEM image of the film grown at room temperature. The squared region enlarged in Fig. 9(b) shows a grain oriented along a simple zone axis. The Fast Fourier Transform (FFT) in Fig. 9(c) of the enlarged region allowed the lattice plane spacing as well as the angles between the different plane families to be measured. The (112), (-112), and (400) planes are identified and the pattern is perfectly compatible with the $[0,2,-1]$ projection of the cubic bixbyite ITO structure. Regarding the film grown at $150{ }^{\circ} \mathrm{C}$ [Figs. 10 (a)-(c)] similar grains are observed but another family of crystallites is also present. The middle part of Fig. 10(a) is an example of a grain different from the cubic bixbyite ITO structure. Indeed, the FFT pattern of the enlarged region of the HRTEM image in Fig. 10(b) reveals the (011), (-101), and (110) planes of the tetragonal In phase and the corresponding angles are consistent with the $[-1,1,-1]$ zone axis of the structure. These results confirm those revealed by the SAED patterns of Figs. 8(a) and 8(b).

\section{DISCUSSION}

Following Nagarajan et al. ${ }^{33}$ the driving force of phase separation in oxygen deficient metastable oxide is the crystallization of the most thermodynamically stable phase. In
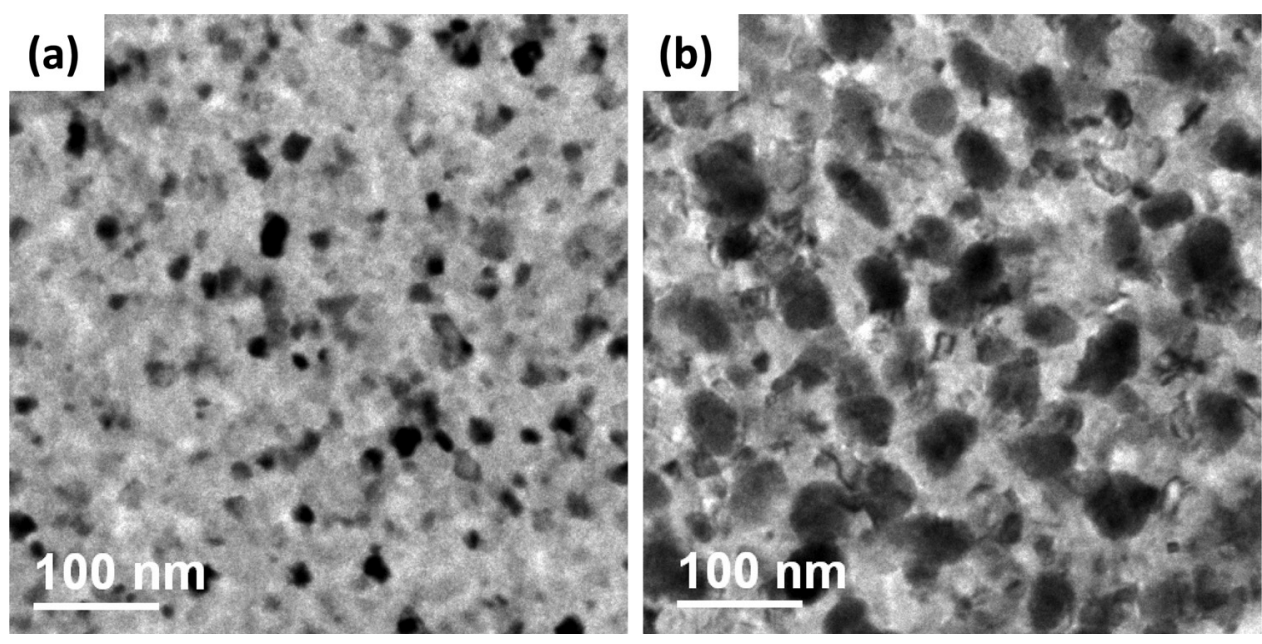

FIG. 7. Dark field images of ITO films grown on a TEM cooper grid at (a) room temperature and (b) $150^{\circ} \mathrm{C}$, respectively. 

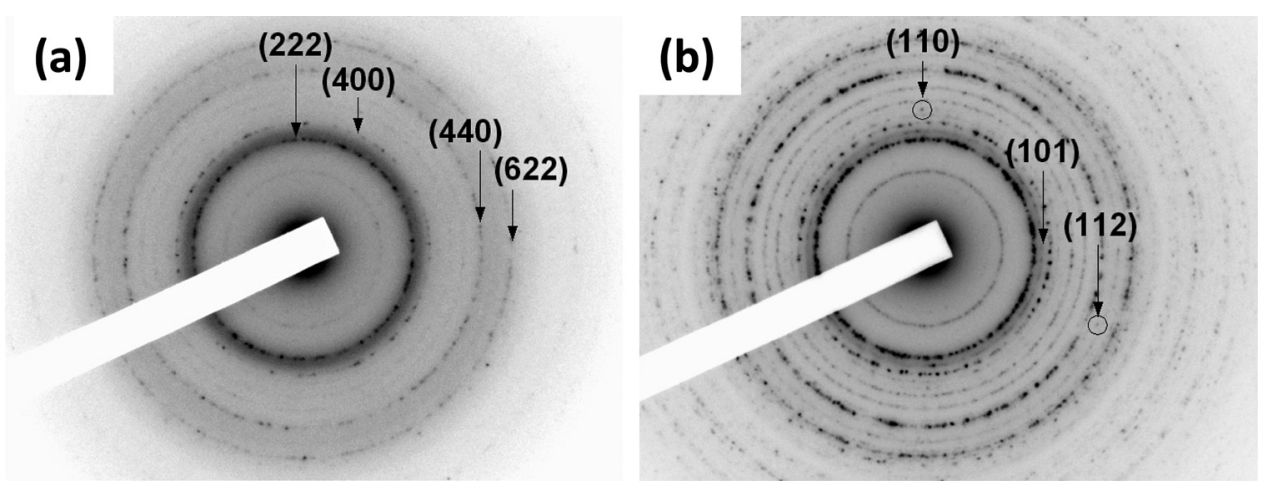

FIG. 8. SAED patterns of (a) the ITO film grown at room temperature and (b) $150{ }^{\circ} \mathrm{C}$, respectively.

the case of the In-Sn-O system, the crystallization of the stable stoichiometric ITO phase will thus occur at the expense of the remaining sub-oxide. This leads to a distribution of more and more oxygen deficient phases as described by the above reaction $(\mathrm{I})$, and in the extreme case $(x=2.4)$, In-Sn nanoclusters can thus be synthesized.

As this phase separation has been observed at room temperature in this work, the oxygen deficiency is the main parameter governing this process. This result seems to be due to a specificity of the PLD growth method. Actually, the kinetic energy of the species emitted by the target during PLD is high (a few tens of eV), and such high energy species will present a high mobility at the surface of the growing film which could favor the formation of crystalline material. The formation of nanocomposite ITO films at room temperature
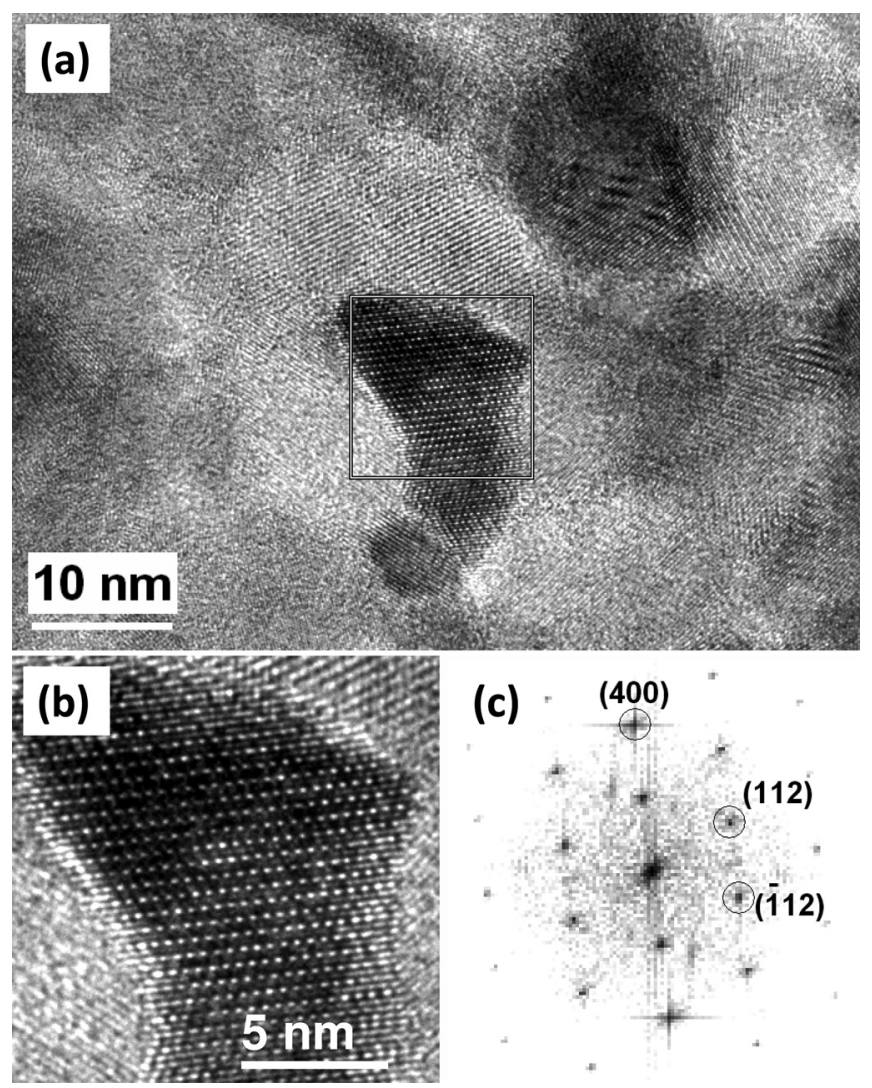

FIG. 9. Plane-view HRTEM micrographs of an individual ITO crystallite $(\mathrm{a}, \mathrm{b})$ and their corresponding fast Fourier transforms (c). by the pulsed electron deposition method (PED) has not been observed, ${ }^{24}$ while the kinetic energy of the emitted species in PED is very similar to that in PLD. ${ }^{36}$ The reason why certainly lies in the very high instantaneous deposition rate in PED, more than $0.2 \mathrm{~nm}$ per pulse, i.e., about 10 times higher than the one currently obtained by PLD. Such a large amount of matter ablated per pulse reaching the surface of the growing film would preclude the formation of crystalline material at room temperature in the ITO oxide films formed by PED.

The results reported in this work, i.e., incomplete superconducting transition and broad and low intensity diffraction peaks, clearly indicate that at room temperature, the density of In-Sn clusters is low and the crystallization of the ITO
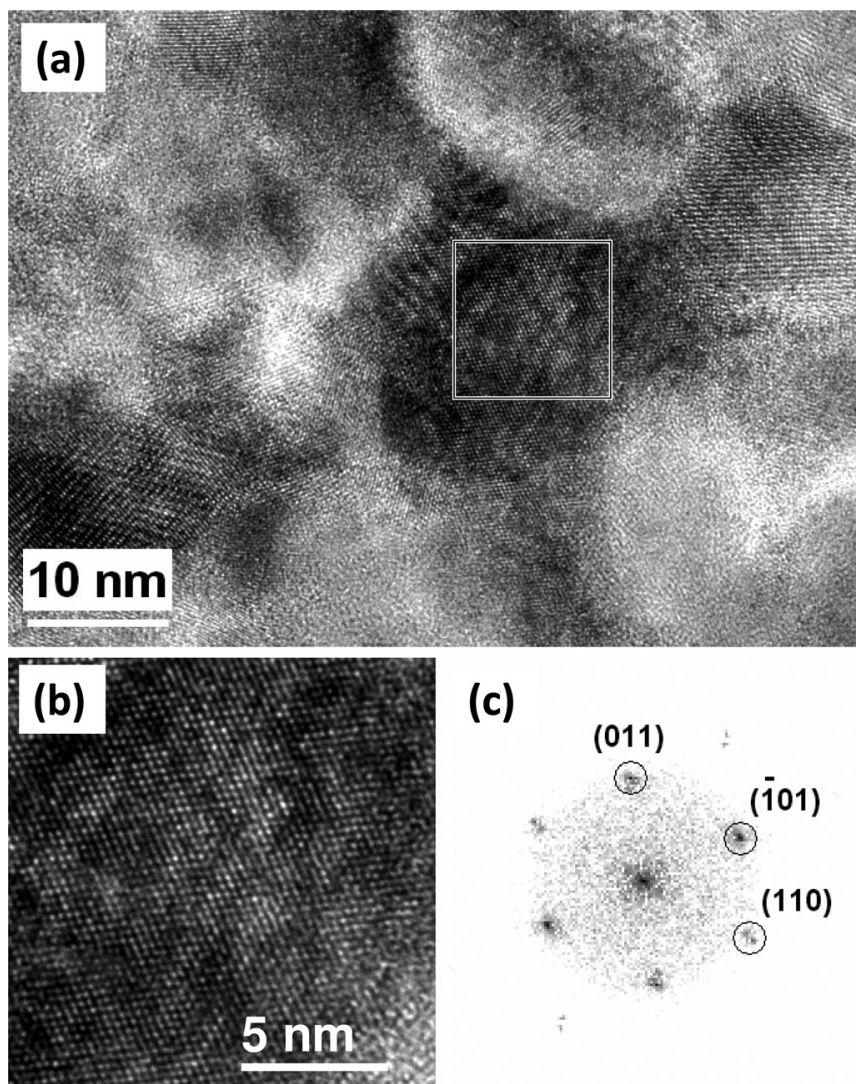

FIG. 10. Plane-view HRTEM micrographs of an In nanocluster in the ITO film grown at $150^{\circ} \mathrm{C}(\mathrm{a}, \mathrm{b})$ and their corresponding fast Fourier transforms (c). 
phase is limited. Upon heating at relatively low $\mathrm{T}(<450 \mathrm{~K})$, the crystallization of both stoichiometric ITO and In-Sn nanoclusters is evidenced. This process seems in particular to be very efficient (see the $\mathrm{R}(\mathrm{T})$ curve) for temperatures higher than $375 \mathrm{~K}$, i.e., once all the In-Sn clusters are in the liquid state, and favoring thus the atomic diffusion needed for the formation of crystalline material.

The formation of stoichiometric ITO at the film-substrate interface will fix the oxygen atoms coming from the external part of the films, and will thus play the role of an oxygen pumping unit in the film. In an extreme situation, the low temperature treatment $(300-450 \mathrm{~K})$ would lead to the formation of a metallic layer at the surface of the film through the complete oxygen depletion. This process could thus partly explain the formation of In metallic grains on the surface of ITO films after annealing under reducing conditions. ${ }^{9,37}$

The low $\mathrm{T}$ transformation of oxygen deficient ITO films (crystallization of stoichiometric ITO and synthesis of In-Sn nanoclusters) leads to an increase of the film conductivity. This increase in conductivity should be related to the formation of more and more oxygen deficient oxide phases as a result of the phase separation. In the extreme case of a complete phase separation with the formation of percolating In-Sn nanoclusters in a stoichiometric ITO matrix, a pure metallic behavior would be observed in the film followed at low $\mathrm{T}$ by a superconducting transition, as it has been recently reported with zero resistivity being observed at $6 \mathrm{~K} .{ }^{38}$ Such a complete phase separation was obtained for films grown at higher $\mathrm{T}(570 \mathrm{~K})$, and was accompanied by a strong optical absorption in the films. ${ }^{38,39}$ Experiments are now in progress to look at the possibility to induce the complete phase separation at $\mathrm{T}<450 \mathrm{~K}$, by increasing the annealing treatment time.

\section{CONCLUSIONS}

In summary, we have shown that nanocomposite ITO thin films can be grown at room temperature by pulsed laser deposition on c-cut sapphire single crystal substrates and under low oxygen pressure $\left(10^{-7} \mathrm{mbar}\right)$. The oxygen deficiency induces a phase separation in the ITO films through a disproportionation reaction, leading to the formation of metallic nanoclusters embedded in an indium tin oxide matrix, i.e., nanocomposite films. The very specific transport properties of the nanocomposite ITO films were correlated with structural investigations.

The phase separation observed in oxygen deficient ITO films could also occur in other oxide materials presenting metastable suboxide phases, leading to the formation of nanocomposite oxide films with interesting conducting and optical properties, as it has been observed in Ga oxide. ${ }^{39}$ Potential applications could thus be envisaged based on laser direct writing processes on such oxygen deficient films to form conducting lines in insulating matrix or dots with refractive index largely different from the matrix. Actually the optical recording based on the metal-insulating transition induced by the large oxygen deficiency in these oxide films could be applied to the next generation of nonvolatile storage devices.

\section{ACKNOWLEDGMENTS}

This work was carried out in part within the cooperative structure around SAFIR, and in the frame of the cooperation between INSP (Université Pierre et Marie Curie-Paris 6) and NILPRP. The authors acknowledge the French network METSA (Microscopie Electronique et Sonde Atomique) for the financial support and facilities.

${ }^{1}$ J. F. Wager, D. A. Keszler, and R. E. Presley, Transparent Electronics (Springer, New York, 2008).

${ }^{2}$ H. L. Hartnagel, A. L. Dawar, A. K. Jain, and C. Jagadish, Semiconducting Transparent Thin Films, Institute of Physics, Bristol (1995).

${ }^{3}$ R. B. H. Tahar, T. Bau, Y. Ohya, and Y. Takahashi, J. Appl. Phys. 83, 2631 (1998).

${ }^{4}$ I. Hamberg, C. G. Grandquist, K. F. Berggren, B. E. Sernelius, and L. Engstroom, Phys. Rev. B 30, 3240 (1984).

${ }^{5}$ R. Mientus and K. Ellmer, Surf. Coat. Technol. 142-144, 748 (2001).

${ }^{6}$ K. Ellmer and R. Mentius, Thin Solid Films 516, 4620 (2008).

${ }^{7}$ Y. Wu, C. H. M. Maree, R. F. Haglund, Jr., J. D. Hamilton, M. A. Morales Paliza, M. B. Huang, L. C. Feldman, and R. A. Weller, J. Appl. Phys. 86, 991 (1999).

${ }^{8}$ M. A. Morales-Paliza, R. F. Haglund, Jr., and L. C. Feldman, Appl. Phys. Lett. 80, 3757 (2002).

${ }^{9}$ C. Sudakar, A. Dixit, S. Kumar, M. B. Sahana, G. Lawes, R. Naik, and V. M. Naik, Scripta Materiala, 62, 63 (2010).

${ }^{10}$ C. W. Ow-Yang, D. Spinner, Y. Shigesato, and D. C. Paine, J. Appl. Phys. 83, 145 (1998).

${ }^{11}$ D. C. Paine, T. Whitson, D. Janiac, R. Beresford, C. Ow Yang, and B. Lewis, J. Appl. Phys. 85, 8445 (1999).

${ }^{12}$ C. Guenther, G. Schierning, R. Theissmann, R. Kruk, R. Schmechel, C. Baethz, and A. Prodi-Schwab, J. Appl. Phys. 104, 034501 (2008).

${ }^{13}$ A. Rogozin, M. Vinnichenko, N. Shevchenko, U. Kreissig, A. Kolitsch, and W. Möller, Scripta Materialia 60, 199 (2009).

${ }^{14}$ A. Rogozin, N. Shevchenko, M. Vinnichenko, F. Prokert, V. Cantelli, A. Kolitsch, and W. Möller, Appl. Phys. Lett. 85, 212 (2004).

${ }^{15}$ H. Nakazawa, Y. Ito, E. Matsumoto, K. Adachi, N. Aoki, and Y. Ochiai, J. Appl. Phys. 100, 093706 (2006).

${ }^{16}$ F. O. Adurodija, L. Semple, and R. Brüning, Thin Solid Films 492, 153 (2005).

${ }^{17}$ S. Gariglio, J. W. Seo, J. Fompeyrine, J. P. Locquet, and J. M. Triscone, Phys. Rev. B 63, 161103 (2001).

${ }^{18}$ S. Degoy, J. Jimenez, P. Martin, O. Martinez, A. C. Prieto, D. Chambonnet, C. Audry, C. Belouet, and J. Perrière, Physica C 256, 291 (1996).

${ }^{19}$ A. Dixit, C. Sudakar, R. Naik, V. M. Naik, and G. Lawes, Appl. Phys. Lett. 95, 192105 (2009).

${ }^{20}$ R. P. Panguluri, P. Kharel, R. C. Sudakar, R. Naik, R. Surynarayanan, V. M. Naik, A. G. Petukhov, B. Nadgorny, and G. Lawes, Phys. Rev. B 79, 165208 (2009).

${ }^{21}$ M. Nistor, F. Gherendi, N. B. Mandache, C. Hebert, J. Perrière, and W. Seiler, J. Appl. Phys. 106, 103710 (2009).

${ }^{22}$ J. Sun and H. Gong, Appl. Phys. Lett. 97, 092106 (2010).

${ }^{23}$ S.-L. Wang, C. Y. Chen, M.-K. Hsieh, W.-C. Lee, A. H. Kung, and L.-H. Peng, Appl. Phys. Lett. 94, 113503 (2009).

${ }^{24}$ M. Nistor, J. Perrière, C. Hebert, and W. Seiler, J. Phys. Condens. Matter. 22, 045006 (2010).

${ }^{25}$ M. Nistor, F. Gherendi, M. Magureanu, N. B. Mandache, A. Ioachim, M. G. Banciu, L. Nedelcu, M. Popescu, F. Sava, and H. V. Alexandru, Appl. Surf. Sci. 247, 169 (2005).

${ }^{26}$ E. Dewald, M. Ganciu, N. B. Mandache, G. Musa, M. Nistor, A. M. Pointu, I. Iovitz Popescu, K. Frank, D. H. H. Hoffmann, and R. Stark, IEEE Trans. Plasma Sci. 25, 279 (1997).

${ }^{27}$ M. Morcrette, A. Gutierrez-Llorente, W. Seiler, J. Perrière, A. Laurent, and P. Barboux, J. Appl. Phys. 88, 5100 (1999).

${ }^{28}$ L. R. Doolittle, Nucl. Instr. and Meth. B9, 344 (1985).

${ }^{29}$ N. Chaoui, E. Millon, J. F. Muller, P. Ecker, W. Bieck, and H. N. Migeon, Appl. Surf. Sci. 138, 256 (1999).

${ }^{30}$ J. Gonzalo, C. N. Afonso, and J. Perrière, J. Appl. Phys. 79, 8042 (1996).

${ }^{31}$ A. F. Hebrard and S. Nakahara, Appl. Phys. Lett. 41, 1130 (1982).

${ }^{32}$ A. T. Fiory, A. F. Hebrard, and W. I. Glaberson, Phys. Rev. B 28, 5075 (1983). 
${ }^{33}$ L. Nagarajan, R. A. De Souza, D. Samuelis, I. Valov, A. Börger, J. Janek, K. D. Becker, P. C. Schmidt, and M. Martin, Nat. Mater. 7, 391 (2008).

${ }^{34}$ R. R. Shen, F. Q. Zu, Y. Xi, F. X. Li, G.H. Din, and H. M. Liu, Phys. Scr. 73, 184 (2006).

${ }^{35}$ A. Petitmangin, C. Hebert, J. Perrière, B. Gallas, L. Binet, P. Barboux, and P. Vermaut, J. Appl. Phys. 109, 013711 (2011).
${ }^{36}$ M. Nistor, N. B. Mandache, and J. Perrière, J. Phys. D: Appl. Phys. 41, 165205 (2007).

${ }^{37}$ J.-H. Lan and J. Kanicki, Thin Solid Films 304, 123 (1997).

${ }^{38}$ M. Nistor, A. Petitmangin, C. Hebert, and W. Seiler, Appl. Surf. Sci. 257, 5337 (2011).

${ }^{39}$ A. Petitmangin, Ph.D. thesis, Université Paris, 2010. 